\title{
A genealogia como programa de pesquisa naturalista
}

\author{
André Luís Mota Itaparica \\ Universidade Federal do Recôncavo da Bahia
}

\section{RESUMO}

Nietzsche não apenas estava atento às contribuições que as ciências poderiam fornecer à psicologia moral como também defendia a elaboração de uma filosofia moral cientificamente informada. Este artigo tem dois objetivos: apresentar uma leitura naturalista do programa genealógico de Nietzsche e relacioná-lo com concepções recentes de genealogia na filosofia moral. Para isso, o artigo enfrenta duas questóes: em primeiro lugar, se a leitura naturalista que toma Nietzsche como filiado à tese metodológica da continuidade entre ciência e filosofia é justificada; em segundo lugar, se Nietzsche oferece alguma solução para o tradicional problema filosófico da relação entre descrição e normatividade.

\section{PALAVRAS-CHAVE}

Genealogia; Naturalismo;

Normatividade; Ciência; Filosofia.

\begin{abstract}
Nietzsche was not only attentive to the contributions empirical sciences could make to moral psychology, but he also advocated the development of a scientifically informed moral philosophy. The purpose of this paper is twofold: it starts defending a naturalistic reading of Nietzsche's genealogical program and then relates it to contemporary genealogical approaches to moral philosophy. In order to achieve this objective, the paper addresses two main questions: first, how justified is the naturalistic reading that takes Nietzsche to be committed to the methodological thesis of the continuity between science and philosophy; second, what kind of solution (if any) Nietzsche offers to the traditional philosophical concerns involving the relationship between the descriptive and the normative.
\end{abstract}

\section{KEY WORDS}

Genealogy; Naturalism;

Normativity; Science; Philosophy. 


\section{Introdução}

"Genealogia", no sentido literal, consiste na reconstituição da linhagem de um indivíduo ou família, por meio da construção de uma árvore de antepassados cujas raízes devem ser as mais longínquas possíveis de alcançar. Em seu sentido figurado, é a busca pela origem de uma concepção ou um evento histórico. Mas foi Nietzsche quem lhe atribuiu um sentido filosófico e estritamente técnico, como uma investigação naturalista das origens da moralidade, em continuidade de métodos e resultados com a melhor ciência de sua época.

Nietzsche não apenas estava atento às contribuições que as ciências poderiam fornecer à filosofia como também considerava imprescindível a elaboração de uma filosofia cientificamente informada. Na nota final da primeira dissertação de Genealogia da Moral, Nietzsche define claramente o método genealógico como um programa de pesquisa indisciplinar, no qual se congregam diversas ciências (da natureza e do espírito) que poderiam contribuir com o propósito de investigar as origens naturais da moral. Assim, podemos identificar em sua genealogia elementos da história, da etimologia, da psicologia, da medicina, da fisiologia, da etnologia e da antropologia do direito. "Genealogia" tornou-se atualmente um vocábulo comum no vasto e variado território daqueles que defendem um projeto de pesquisa de naturalização da moral e de elaboração de uma ética naturalista na filosofia contemporânea e nas ciências naturais, batizado com os mais diversos nomes: sociobiologia, psicologia evolucionista ou ética evolucionista.

A genealogia nietzschiana busca, de um lado, uma explicação natural da emergência dos conceitos morais; de outro, ela critica os valores estabelecidos e anuncia a possibilidade de novos valores. Assim, ela possui tanto um aspecto descritivo quanto um prescritivo. $\mathrm{O}$ aspecto descritivo levanta a questão de como se dá a continuidade entre ciência e filosofia, e se essa relação conduz a um reducionismo fisicalista. $\mathrm{O}$ aspecto prescritivo leva à questão se Nietzsche não incorreria na chamada "falácia naturalista", designação que significa duas coisas distintas: uma dedução vetada do factual ("ser”) para o prescritivo ("dever ser”), como em David Hume, ou numa definição do "bem" em termos de propriedades naturais, como em G. E. Moore). I' O projeto genealógico de Nietzsche precisa enfrentar, portanto, duas questôes atuais e centrais na discussão sobre o naturalismo ético: em primeiro lugar, o problema da continuidade entre ciência e filosofia; em segundo lugar, o problema da relação entre descrição e normatividade.

Não à toa, um dos debates atuais da pesquisa Nietzsche realiza-se em torno da questão de qual seria a melhor forma de definir o naturalismo do filósofo. Que em Nietzsche há um programa naturalista, não há como discordar. Desde

I Para entender essas duas acepções, e a confusão entre elas. Cf. Joyce, 2006, pp. I46-I56. 
Humano, Demasiado Humano, Nietzsche desenvolve uma análise da moralidade que prescinde de explicaçóes de caráter transcendentes, pretendendo ter como modelo para a filosofia o método científico. ${ }^{2}$ Essa tendência é aprofundada em Aurora, onde Nietzsche, por exemplo, estabelece uma clara continuidade entre comportamentos animais e virtudes morais. ${ }^{3}$ Em Para além de Bem e Mal, Nietzsche apresenta, em tom programático, a ideia de uma história natural da moral ${ }^{4}$, que será desenvolvida com a elaboração do projeto de uma genealogia da moral. Num texto paradigmático desse projeto, Nietzsche propõe justamente a naturalização como uma forma de evitar uma concepção transcendentalizada do homem, para que, por meio dela, se possa, apoiado na "disciplina da ciência", "retraduzir o homem de volta à natureza", destituindo o homem de suas interpretaçôes lisonjeiras e apresentando por fim o "terrível texto original [Grundtext] homo natura".

Em tempos recentes, principalmente na literatura de língua inglesa, que possui uma forte tradição naturalista, esse aspecto da filosofia de Nietzsche foi particularmente ressaltado. Podemos mencionar, por exemplo, Daniel Dennett, em A Perigosa Ideia de Darwin, que já considerava Nietzsche como um precursor da sociobiologia, até trabalhos mais recentes de autores como Bernard Williams, Brian Leiter, Christa Davis Acampora, Christopher Janaway, Maudemarie Clark e David Dudrick e Richard Schacht. ${ }^{6}$ Além desses trabalhos, autores da sociobiologia, da psicologia evolucionista e da ética naturalista percorrem esse caminho anteriormente trilhado por Nietzsche, Paul Rée, utilitaristas e materialistas (Engels) ${ }^{7}$, e que teve em sua origem o próprio Darwin. Apresentar uma leitura naturalista do projeto genealógico e relacioná-lo com concepções recentes de genealogia é o propósito deste artigo. Para isso, naturalmente, teremos de apresentar uma resposta nietzschiana, mesmo que provisória, ao problema da relação ciência/filosofia e descrição/normatividade.

\section{Breve contextualização histórica da genealogia}

Num volume dedicado ao tema Nietzsche e as Ciências, seus autores, Gregory Moore e Thomas Brobjer, aliando descrição do contexto histórico a uma cuidadosa pesquisa de fontes, debatem o contexto do projeto naturalista de Nietzsche, que

2 Humano, Demasiado Humano $₫$ I, $\$ 3, \$$ 6, KSA 2.23-24; KSA 2.25-26, KSA 2.27-8.

3 Aurora $\$ 26$. KSA 3.36-37.

4 Para além de Bem e Mal\$ I86, KSA 5.I05-I07.

5 Para além de Bem e Mal \$230, KSA 5.I67-I70.

6 Dennett, I998; Williams, 20II; Leiter, 2002; Acampora, 2006; Janaway, 2007; Clark \& Drudrick, 2006; Schacht, 200I, 20II, 2012.

7 Para uma comparação entre a genealogia dos utilitaristas, dos materialistas e de Nietzsche, Cf. Prinz, 2016. 
não destoa de uma série de iniciativas assumidas na época. Como lembra Moore, na introdução do livro, estamos falando da segunda metade do século XIx, quando, ao mesmo tempo que se assiste a um desenvolvimento gigantesco da ciência e da tecnologia, a escola filosófica outrora hegemônica, do idealismo alemão (e sua filosofia da natureza), parece cair em total descrédito. A filosofia, assim, teve de redescobrir seu lugar, seja como história da filosofia rigorosa (Otto Liebmann e Kuno Fischer), exortando a uma volta a Kant como modelo de filosofia ainda em diálogo com a ciência, ou como uma aplicação direta dos resultados científicos, como no materialismo alemão. Nietzsche não opta por nenhuma dessas duas posiçōes, adotando uma terceira, mais sofisticada filosoficamente, que procurava debater com as ciências sem recair num materialismo vulgar, posição assumida tanto por filósofos cientificamente informados, como Friedrich A. Lange, Eduard von Hartmann e Eugen Dühring, quanto por cientistas filosoficamente informados, como Helmholtz e Ernst Mach. ${ }^{8}$

Sobre a questão da moralidade, Darwin já havia lançado a pedra fundamental, que foi seguida pelos "genealogistas ingleses" e de certa forma ainda modela as pesquisas atuais sobre as origens naturais da moralidade. Considerando a consciência moral como a característica que mais diferencia o homem dos outros animais, Darwin se propõe a discuti-la de um ponto de vista da história natural: a moralidade, como um fenômeno unicamente humano, pode ser analisada à luz da história natural (no caso, a teoria da evolução pela seleção natural). Dessa perspectiva, certos traços de antepassados humanos devem ter sido preservados por sua aptidão para a sobrevivência. Entre eles, Darwin menciona os instintos sociais e as relaçóes de parentesco como fatores predominantes para a preservação de caracteres que posteriormente resultariam, com o surgimento de faculdades cognitivas superiores, na constituição de uma consciência moral. Atualmente, o vocabulário biológico, mesmo que modificado, mantém a mesma estrutura: a fim de garantir sua contribuição no pool genético, indivíduos que possuem traços altruístas apresentam vantagens reprodutivas, numa escala que parte da seleção de parentesco até a seleção de grupo. A moralidade, assim, se baseia em nossos instintos sociais e nos traços altruístas. Esse caminho foi seguido, à sua maneira, mas em grande proximidade a Darwin, por Paul Rée, interlocutor privilegiado de Nietzsche, em $A$ Origem dos Sentimentos Morais. ${ }^{9}$ Como se pode ver, nada mais antinietzschiano: gregariedade e altruísmo como base da moralidade. Ao mesmo tempo, nada mais nietzschiano: uma busca por uma explicação natural da moralidade.

8 Moore \& Brobjer, 2004. Cf. também: Lopes, 2011.

9 Rée, 2004. 


\section{Naturalismo na pesquisa Nietzsche}

Em seu livro Nietzsche on Morality, Brian Leiter apresenta sua tese central sobre o naturalismo em Nietzsche, que ocupará um lugar central nesse debate. Para Leiter o naturalismo metodológico é a tese segundo a qual a pesquisa filosófica deve estar em linha de continuidade com a ciência empírica, seja a ciência compreendida exclusivamente como ciência natural (naturalismo hard) ou, numa versão liberal, que inclua também as ciências sociais (naturalismo soft). Essa continuidade pode ser vista como continuidade de métodos (a filosofia emula os métodos científicos) ou uma continuidade de resultados (a filosofia apoia suas teses em resultados das ciências empíricas). Nietzsche, como Hume, seria um naturalista de continuidade de métodos, do tipo especulativo: toma um paradigma científico como modelo e aplica suas diretrizes a problemas filosóficos. Sendo assim, Nietzsche seria predominantemente um naturalista metodológico, tanto no aspecto de continuidade de métodos quanto no de resultados. $\mathrm{Na}$ análise da moralidade, uma tese central atribuída por Leiter ao naturalismo de Nietzsche, e que vai direcionar sua leitura, é a "doutrina dos tipos", segundo a qual cada pessoa possui uma constituição psicofísica fixa que a determina como um tipo particular.

Essas teses de Leiter sofreram uma série de críticas por parte de vários comentadores. Essas críticas se concentraram na questão se Leiter não teria uma concepção reducionista e cientificista de naturalismo, deixando de lado a dimensão cultural e, portanto, a possibilidade de um naturalismo mais liberal. Essa é a posição de Richard Schacht, por exemplo. Para ele, o naturalismo de Nietzsche consistiria simplesmente em elaborar teses filosóficas que não entrassem em conflito com as ciências, não fizessem referências a entidades que extrapolassem o âmbito dos fenômenos empíricos e nossa localização no interior da natureza. Desse ponto de vista, Nietzsche seria um naturalista em sentido bastante amplo. Ele não necessitaria, para elaborar suas teorias especulativas, de recorrer apenas a resultados das ciências empíricas. O naturalismo de Nietzsche se basearia em hipóteses imaginativas que teriam como critério de aceitação sua plausibilidade. Esse naturalismo nada mais seria que uma hipótese reguladora, e não implicaria, portanto, a assunção de compromissos ontológicos fortes; em termos metodológicos, seria um princípio heurístico, e não a emulação de procedimentos científicos. Assim, mais que procurar uma continuidade restrita às ciências naturais, o naturalismo de Nietzsche consistiria em articular diversos pontos de vista, não só das ciências naturais, mas da cultura como um todo, reconhecendo a historicidade das Lebensformen que a cultura constitui e que não podem ser reduzidas a fenômenos psicofísicos.

Nisso Christopher Janaway segue de perto o posicionamento de Schacht. Também para ele o naturalismo de Nietzsche pode ser entendido de forma am- 
pla como uma orientação geral de escapar de todo resíduo transcendente nas teorias filosóficas. Compreendendo o naturalismo dessa forma ampliada, Janaway considera que Leiter teria exagerado na continuidade entre a filosofia de Nietzsche e as ciências empíricas. Desse modo, Janaway conclui com a defesa de um naturalismo não só mais liberal como também mais deflacionado do que aquele que ele encontra em Leiter.

O cerne da objeção de Schacht e Janaway ao conceito restrito e cientificista de naturalismo que eles encontram em Leiter pode ser resumido pela seguinte passagem de Janaway, na qual ele argumenta como uma explicação naturalista de Nietzsche não pode prescindir do seu aspecto cultural, que estruturaria nossas crenças valorativas originadas de nosso mundo afetivo:

Mas, se a consideração esquemática que ofereci aqui for de algum modo próximo do correto, podemos sugerir uma interpretação mais articulada da posição naturalista de Nietzsche. Não se trata simplesmente que minhas crenças valorativas são explicadas por minha constituição psicofísica: mas antes que minhas crenças valorativas são racionalizações, que minhas inclinações e aversōes são hábitos adquiridos inculcados por meio da cultura específica em que estou inserido, que essa cultura inculca justamente esses hábitos porque ela possui a estrutura orientadora das crenças valorativas, e que essa estrutura se tornou dominante ao responder a certas necessidades afetivas de indivíduos em estádios culturais anteriores. ${ }^{10}$

Em texto posterior, "O naturalismo de Nietzsche reconsiderado", Leiter, obrigado a responder a essas questôes, acaba por retroceder em suas posiçôes de tom mais cientificistas. ${ }^{\text {II }}$ Leiter permanece dando prioridade ao ponto de vista psicofísico em relação ao cultural, e considerado a possibilidade de falseamento empírico de teses psicológicas de Nietzsche. Mas admite agora que, ao se apoiar em resultados científicos, o naturalismo de Nietzsche deixa de ser meramente metodológico e traz também um aspecto substantivo. Além disso, ao apresentar o que seria uma confirmação do sucesso das teses naturalistas de Nietzsche ao que se foi posteriormente descoberto pelas ciências empíricas, Leiter revela compreender o naturalismo de Nietzsche de uma forma muito mais liberal do que até então ele dera a entender. Apoiado num texto escrito com Jushua Knobe, Leiter procura explicitar que teses de Nietzsche antecipariam teses contemporâneas no âmbito da psicologia moral, concluindo que introspecção, a literatura e a história foram fontes das descobertas de Nietzsche,

IO Janaway, 2007, p. 47.

II Leiter, 20II. 
e não exclusivamente as ciências empíricas. ${ }^{\mathrm{I2}}$ Isso mostra que até mesmo Leiter, ao fim e ao cabo, não possui uma concepção tão dura do naturalismo de Nietzsche, pelo menos quando tem de justificar as bases naturais de suas teorias.

\section{Avaliação do debate}

\subsection{Continuidade entre ciência e filosofia}

Mais importante que acompanhar o debate em torno do conceito de naturalismo de Nietzsche é tentar compreender o que toda essa disputa entre Leiter e seus críticos sinaliza. Antes de mais nada, por fazer parte de uma tradição em que naturalismo é frequentemente identificado com reducionismo fisicalista, o debate todo se desenvolve no sentido de compreender o naturalismo em Nietzsche dentro dessa tradição, mas fazendo concessões necessárias, já que não há como identificar Nietzsche com um projeto de continuidade direta entre filosofia e ciências naturais. Leiter é quem procura menos conceder a um naturalismo liberal, embora ele tenha de explicitar a divergência de Nietzsche com um determinado projeto reducionista e, como vimos, não possa manter uma posição muito fechada até o fim.

É certo, contudo, que a discussão sobre a continuidade entre ciência e filosofia não só era presente como também era central na época de Nietzsche, quando, após a derrocada do idealismo alemão, a filosofia teve de reduzir suas pretensões metafísicas sistemáticas e procurar um novo lugar através do diálogo com as ciências naturais. Mas a diferença consiste no fato de que, para Nietzsche, associar-se até mesmo a um reducionismo fisicalista não significaria adotar um materialismo corpuscular. É o que Nietzsche afirma no seguinte fragmento póstumo: "Quando penso em minha genealogia filosófica, sinto-me em relação com [...] o movimento mecanicista (recondução de todas questões morais e estéticas a fisiológicas, de todas fisiológicas a químicas, de todas químicas a mecânicas), mas com a diferença de que não acredito na 'matéria' e considero Boscovich [...] como um dos grandes pontos de virada". ${ }^{\text {I3 }}$

Ora, Nietzsche defende aqui claramente um reducionismo, mas a física já não é mais atomística. Isso mostra, em primeiro lugar, que Nietzsche tem a possibilidade de assumir um reducionismo que não precisa ser materialista (corpuscular), algo que o próprio Leiter reconhece. Mas isso abre margem para um segundo ponto, pouco discutido nesse debate: a existência de um naturalismo substantivo em Nietzsche, ou seja, o fato de ele assumir compromissos ontológicos fortes. Pois, por mais que possamos relativizar o estatuto positivo da vontade de potência

I2 Knobe \& Leiter, 2009, pp. 9I-IO3.

I3 Fragmento Póstumo 26 [432] do verão/outono de I884, KSA II.266. 
e o caráter meramente provisório de sua formulação, principalmente nos livros publicados, ela acaba por desempenhar um papel importante em seu naturalismo, e com isso leva à formulação de teses fortes, mesmo que, como Schacht apontou corretamente, possamos entender esse naturalismo substantivo como uma hipótese reguladora. De qualquer modo, podemos citar aqui algumas teses de Nietzsche que guardam esse caráter substantivo e vinculam a filosofia teórica de Nietzsche a sua filosofia prática: o mundo é um conjunto de forças em conflito e em processo de expansão; essas forças expressam-se no orgânico como impulsos psicofísicos [Triebe]; os impulsos humanos visam assim ao seu aumento e ao conflito; os homens, como seres naturais, são sequiosos de poder e uma análise da moralidade não pode deixar de sublinhar esse fato, sobretudo em seu aspecto psicológico. Nietzsche, nesse sentido, estava sendo não só um naturalista metodológico de continuidade de métodos e resultados (o que ele faz de forma muito mais liberal do que Paul Rée, por exemplo), como também tendo que arcar com uma de suas consequências, que é a ter de assumir um ponto de vista substantivo, ao assumir teses que dialogam com as ciências de sua época (como sua posição contrária ao atomismo e a certos aspectos do darwinismo).

Essa discussão sobre o naturalismo substantivo de Nietzsche, contudo, não toma um lugar de destaque no debate sobre o naturalismo de Nietzsche por um motivo óbvio: não é certo se a teoria da vontade de potência pode estar estritamente em continuidade com a ciência empírica ou ser capaz de satisfazer critérios de cientificidade atuais (se ela é passível de alguma forma de verificação ou falseamento). Nesse caso, aparece aí um problema de demarcação que acaba colocando em xeque as pretensões de um naturalismo duro em Nietzsche. Por isso Leiter não tem o que fazer senão tentar admitir essa teoria apenas em seu aspecto psicológico e tentar manter Nietzsche no âmbito de um naturalismo metodológico, tendo como modelo científico a fisiologia (tendo para isso de esquecer que também a fisiologia, no sentido que Nietzsche emprega em sua doutrina dos tipos, que Leiter corretamente reconhece, também estará apoiada na mesma ontologia que ele descarta). Mas o fato é que um problema talvez insolúvel em Nietzsche é o estabelecimento final do estatuto da vontade de potência, o que torna problemática também a compreensão de um naturalismo substantivo em Nietzsche, assim como a plausibilidade de suas teses.

Uma forma de escapar da aceitação de um naturalismo substantivo em Nietzsche é fazer, como fazem os críticos de Leiter, uma leitura de Nietzsche não mais tão vinculada a um cientificismo reducionista, mas apoiada nas contribuições culturais ao naturalismo de Nietzsche. A ideia é que o naturalismo de Nietzsche não pode ser compreendido somente à luz das ciências naturais, 
mas no contexto da cultura. Essa é a ideia de Schacht, em sua concepção dos sentimentos incluídos no rol dos objetos naturais, e de Janaway, quando vê o mundo afetivo como resultado de hábitos que são fixados culturalmente. ${ }^{\mathrm{I}}$

\subsection{Naturalismo e normatividade}

Bernard Williams comentou que a grande maioria dos filósofos concorda que a psicologia moral, em nossa época, precisa assumir um ponto de vista naturalista; o que não sabemos, diz ele, é como compreender e tornar realidade esse "feliz e amplo consenso". 'De fato, parece que, com essa questão, esbarramos num dilema: quando se fala em naturalismo, ou se exclui demais, se não se observa o papel da cultura, ainda mais se considerarmos que esta faz parte da etologia da espécie, ou se exclui de menos, quando se permanece procurando salvaguardar a nossa auto-imagem em relação à moralidade. Assim, ou cairíamos em um reducionismo fisicalista, ou encontraríamos um lugar especial para a moralidade, e com isso nos afastaríamos do naturalismo. A resposta de Williams é que Nietzsche pode ser melhor caracterizado como um realista: aquele que propóe uma psicologia moral minimalista, depurando-a do excesso moral em suas análises. Embora defendamos um naturalismo mais forte em Nietzsche, consideramos que Williams aponta aí um caminho promissor: a cultura não deve ser desnaturalizada. Uma leitura naturalista de Nietzsche não pode contrapor natureza e cultura, mas reconhecer a cultura como um processo natural, mesmo que isso venha a significar uma nova forma de vida, e, portanto, uma nova relação com os instintos herdados, que gerarão novos comportamentos.

Essa proposta de Williams pode ser uma resposta razoável para a questão da relação de continuidade entre ciência e filosofia. Mas ainda não resolve a questão de como compreender a normatividade em Nietzsche sem recair na chamada falácia naturalista. Pois, apesar do caráter ainda inconcluso de sua proposta normativa - e da dificuldade de lidar com o estatuto de conceitos como o eterno retorno e o amor fati - é certo que essa proposta pretende ser uma forma mais apropriada de o homem se relacionar com sua própria natureza, negada pela moral cristã por meio do ideal ascético.

A primeira questão a ser investigada é se a genealogia de fato possui um aspecto prescritivo ou se é um método meramente descritivo, debate bastante

I4 Concepção defendida por alguns contemporaneamente: "O naturalismo liberal, tal como o entendemos, não é precisamente um credo definido. É melhor vê-lo como uma gama de tentativas de articular uma nova forma de naturalismo que visa fazer justiça à gama e à diversidade de ciências, incluindo as sociais e humanas (livre de equívocos positivistas) e à pluralidade de formas de compreensão, inclusive à possibilidade de formas de compreensão não-científicas e não-supernaturais”. De Caro \& Macarthur, 2oıo, p. 9.

I5 Williams, 20II, p. I9. 
presente na literatura atual. ${ }^{16}$ De fato, à primeira vista a genealogia é apenas uma tentativa de reconstituir a trajetória que consuziu o homem de seu passado pré-histórico ao estabelecimento e internalização de normas morais. O que habitualmente é ressaltado na genealogia é seu aspecto crítico. Seu propósito ou se reduziria a uma crítica da moral vigente ou, no máximo, a um desmascaramento da moral como uma ilusão ${ }^{17}$ e o estabelecimento de um ponto de vista além da moral. Além disso, o próprio Nietzsche considera Para além de Bem e Mal e Genealogia da Moral como o lado negativo da transvaloração.

Não devemos esquecer, contudo, que a crítica já pressupóe uma avaliação. No prefácio da Genealogia, Nietzsche deixa claro que a grande diferença entre ele e sua obra anterior (e a dos genealogistas ingleses, sobretudo) é que ele não se limitou a uma genealogia meramente descritiva, mas que também passou a ter um ponto de vista avaliativo dos próprios valores morais, o que já pressupõe a prescrição do que seriam formas de vida superiores: "Alguma educação histórica e filosófica, acrescida sobretudo de um sentido exigente em relação a questôes psicológicas, logo transformou meu problema em outro: sob que condiçôes o homem inventou para si os juízos de valor bom e mau? Eque valor eles próprios têm? Até então obstruíram ou promoveram o florescimento humano?". "A oposição de Nietzsche à "genealogia inglesa", portanto, é mais de conteúdo do que de método. Nietzsche quer reconstruir uma outra origem da moralidade, sem os vícios de uma mentalidade utilitarista. Mas nem por isso Nietzsche nega que ele pertence a uma tradição genealógica: ele apenas propõe uma nova descrição, para ele mais plausível. E além dessa descrição, ele se propõe a questionar os valores que tradicionalmente nortearam a moral e que deram um viés anacrônico à "genealogia inglesa", que, por falta de sentido histórico, assumiu tacitamente esses valores e incorreu numa falácia genética, ao identificar a função atual de uma prática ou conceito à sua função original.

Com sua crítica à genealogia utilitarista, Nietzsche revela o aspecto normativo da genealogia, que se insere num contexto maior de crítica ao niilismo e no projeto de uma transvaloração dos valores. O problema do niilismo serve como pano de fundo da narrativa (mencionado diversas vezes na Genealogia),

I6 Numa resenha a uma coletânea sobre a Genealogia, Martin Saar e Hannah Grosse Wiesmann ressaltam a importância dessa questão: "Como era de esperar, discussões recentes estão ainda circulando em torno da questão se o modo genealógico de argumentação é essencialmente histórico ou não (comparar de Katsafanas e Geuss a Kail ou Hussain), ou se Nietzsche nos fornece alternativas substantivas às formas de vida 'decadentes' e 'fracas' que ele ataca, ou se sua empresa permanece mais ou menos negativa (comparar de Swanton a Leiter” (Saar \& Wiesmann, 20I2).

I7 Como o agnosticismo moral defendido por Joyce, 2006, por exemplo.

I8 Genealogia da Moral, Prólogo, $\$ 3$. 
e a evocação de Zaratustra (também presente na Genealogia) mostra que uma posição normativa já está pressuposta. Embora o projeto normativo de Nietzsche nunca tenha se realizado formal e sistematicamente de forma acabada (o que ele esperava realizar numa obra futura e termina por considerá-lo acabado no Anticristo), é certo que possuímos elementos suficientes para reconstituí-lo: trata-se de um projeto de superação da moral cristã, continuada pelas propostas modernas de moral normativa (deontologia e utilitarismo), através do cultivo de virtudes que promovam o florescimento humano. ${ }^{19}$

Ora, se admitirmos esse caráter normativo, temos de compreender quais são as fontes da normatividade nietzschiana, assunto também discutido mas pouco aprofundado na literatura. Quanto a isso, quem talvez tenha avançado mais nessa questão tenha sido Richard Schacht, ao contrapor o que seria a resposta de Nietzsche sobre as fontes da normatividade às quatro opçôes mencionadas por Christine Korsgaard (das quais ela opta pelas duas últimas): as que se baseiam na autoridade externa, num realismo axiológico, na natureza reflexiva humana ou na vontade de agentes racionais. Para Schacht, Nietzsche se diferencia na própria colocação da pergunta: não se trata de justificar a força normativa da moral, mas entender como o fenômeno da normatividade pode ser entendido a partir de um ponto de vista naturalista. A resposta que Schacht apresenta consiste em ver as raízes da normatividade da moral nietzschiana não na racionalidade humana, mas em seus afetos, que se constituem em forma de vida que produzem disposições (sensibilidades). Essas sensibilidades provocam a adoção, identificação e internalização de normas, que são seguidas não num modelo kantiano (como obediência à lei da razão), mas num modelo wittgensteiniano de seguir regras (como ocorre numa língua e nas normas sócio-culturais).

O mais importante da interpretação de Schacht é apontar para a existência de uma normatividade em Nietzsche e para a raiz dessa normatividade nos afetos. Ele não investiga, no entanto, como Nietzsche descreve em termos naturalistas a interiorização das normas e como ele poderia fomentar uma nova normatividade que tivesse efeito nos afetos, como faz toda moral. Na realidade, Nietzsche já havia mostrado como uma espécie internalizou a moralidade, assunto da segunda dissertação da Genealogia da Moral. Como cultivar novas sensibilidades e virtudes superiores, assim como internalizá-las é algo que Nietzsche deixou algumas pistas em passagens de Para além de Bem e Mal, por exemplo. Em algumas, vemos que ele já compreendia a capacidade de internalização das normas como algo incorporado à espécie. ${ }^{20}$ Outras passagens parecem não afastar Nietzsche inequivoca-

I9 Para Brobjer, I995, por exemplo, Nietzsche defende uma forma de ética das virtudes.

20 Para além de Bem e Mal $\$$ I88. KsA 5.Io8-IIo. 
mente da chamada "falácia naturalista" ${ }^{21}$, quando ele se aproxima do discurso da degenerescência e parece flertar com concepções eugenistas. Essas questôes devem ser discutidas para que possamos ter uma compreensão mais precisa da ética naturalista prescritiva de Nietzsche.

\section{O naturalismo de Nietzsche e as "falácias naturalistas"}

Nosso exame das duas questões centrais do naturalismo, ou seja, em primeiro lugar, a continuidade entre ciência filosofia e, em segundo lugar, a relação entre descrição e normatividade permitiu mostrar que elas encontram respostas plausíveis no contexto da filosofia de Nietzsche: Nietzsche defende um naturalismo liberal e fundamenta a normatividade de sua moral afirmativa nos afetos. Permanece em aberto, no entanto, a questão das "falácias naturalistas" (sua versão original de Moore e a crítica do hiato lógico entre ser/dever, de Hume).

Quanto à falácia naturalista original, de Moore, ela não é considerada uma ameaça séria para a maioria dos filósofos naturalistas da atualidade, como resume Richard Joyce: "[...] O naturalista moral (e ipso facto o naturalista moral evolucionista) pode não ligar muito para essa interdição, pois não está claro que sua empresa seja a de fornecer algo como uma definição decomposta da bondade moral". ${ }^{22}$ Do mesmo modo, ao defender um intucionismo, Moore estaria assumindo um ponto de vista insustentável para um naturalista: o de que teríamos uma forma de acesso direto à "bondade". Pelos mesmos motivos, a objeção de Moore não é uma ameaça seria à ética naturalista prescritiva de Nietzsche. Nietzsche nunca considerou a lógica como critério definidor de questôes morais, por seu caráter abstrato e desprovido de conteúdo. Do mesmo modo, Nietzsche elaborou inúmeras críticas à concepção de qualquer espécie de certeza imediata, por considerar que essa ideia ignora seus pressupostos tácitos. No caso de um intuicionismo moral, este ignoraria que seus próprios valores já são determinados historicamente.

Quanto à "lei de Hume", trata-se de uma questão que atinge mais as tentativas de projetos de éticas naturalistas prescritivas. Como se sabe, essa questão é apresentada numa passagem do Tratado da Natureza Humana. Hume aponta o suposto erro lógico de chegar a conclusões sem derivá-las das premissas. Aqui, no caso, passar-se-ia de juízos de fatos para juízos de valores; eles possuem naturezas distintas, e não há uma ponte lógica entre eles: "Em todo sistema moral que até hoje encontrei, sempre notei que o autor segue por algum tempo

2I Prinz, 20I6, p. I9I.

22 Joyce, 2007, p. I5I. 
o modo comum de raciocinar [...]; quando, de repente, me surpreendo ao ver que, ao invés das cópulas proposicionais usuais, como é e não é, não encontro uma só proposição que não seja conectada a outra por um deve ou não deve" ${ }^{23}$

Joyce lembra que a falácia não está propriamente aqui na sua invalidade, pois é inteiramente possível, utilizando "truques lógicos" deduzir de premissas factuais conclusões normativas. ${ }^{24} \mathrm{Nem}$ se trata, segundo o mesmo autor, da falsa crença de que se algo for natural é bom (o que não seria uma falácia lógica). A questão aqui é que não há uma relação semântica ou dedutiva entre premissa e conclusão. Para Joyce, mesmo neste caso, a lacuna entre ser e dever pode ser facilmente transposta, ao se considerar a passagem como um entimema e se acrescentar a premissa faltante. Assim, para Joyce, também neste caso a ideia de uma ética naturalista prescritiva não é abalada: "Assim, mesmo que a falácia naturalista de Moore e o hiato lógico é/deve ser fossem triunfantes sobre o naturalismo moral, haveria outras vias para serem exploradas pelo defensor da ética evolucionista. Contudo, como vimos, essas considerações estão longe de serem triunfantes. Ambas são irrelevantes e foram eliminadas do debate em meados do século xx". ${ }^{25}$ Além disso, o próprio Hume possui uma moral naturalista, baseada no sentimento de simpatia, o que mostra que seu argumento se dirige muito mais às tentativas de vindicar uma moral a partir de argumento racionalistas.

No caso de Nietzsche, embora muitas vezes ele afirme que valores da moral nobre que ele defende sejam superiores porque possuem propriedades naturais - como o impulso ao domínio que se encontra no núcleo da vida, a vontade de potência, o pathos da distância, o egoísmo, etc. - , ele não defende sua posição como se uma moral fosse superior a outra simplesmente por possuir propriedades naturais (e muito menos iguala o natural ao bom). Ao contrário, ele se pronuncia claramente contra o hedonismo, o pessimismo, o eudemonismo e utilitarismo por se basearem na dor e no prazer como propriedades naturais, em Para além de Bem $e$ Mal. $^{26}$ Nessa passagem, Nietzsche esclarece que a natureza não é um laissez-faire. Portanto, nesse sentido, uma ética naturalista também não estaria desprovida de rígidas normas, cuja interiorização já faria parte da espécie. Mas é desse caráter normativo incrustrado na espécie que puderam surgir obras da cultura, que muitas vezes distanciam o homem, mesmo que relativamente, de seu passado animal pré-histórico. A domesticação do homem (e até mesmo o cristianismo) teve também

23 Hume, 2000, p. 509.

24 A regra da adição disjuntiva e o teorema segundo o qual de uma contradição qualquer coisa se segue (Joyce 2006, pp. I52-I53).

25 Joyce, 2006, p. I55.

26 Para além de Bem e Mal \$225, KSA 5.I60-I6I. 
um papel importante para o refinamento da cultura e das artes.

Apesar dessas versões da chamada "falácia naturalista" não atingirem as éticas naturalistas prescritivas, isso não significa, na opinião de Joyce, que elas sejam sustentáveis. Este último ponto é fundamental para podermos entender, se não de forma exaustiva, mas pelo menos geral, o estatuto do naturalismo na filosofia moral de Nietzsche. Joyce defende que a parte descritiva da ética evolutiva acaba por provocar o debunking da objetividade moral — de qualquer moral —, assumindo um agnosticismo moral: podemos não ter mais a crença na verdade das normas morais, mas, conhecendo sua história evolutiva e sua função, não deixaremos de agir segundo nossas disposiçōes morais.

Em alguns momentos, Nietzsche parece assumir uma posição semelhante: depois de a genealogia ter descrito a origem natural da moral, e com isso destruído a crença na moral cristã, restaria a posição "além do bem e do mal", além da moral, do imoralista: "Já se sabe que palavra se ajusta a mim, nessa luta [contra a moral], a palavra imoralista; conhece-se igualmente minha fórmula 'além do bem e do mal' [...] O que pode um imoralista exigir de si mesmo? [...] Talvez 'melhorar' a humanidade, apenas de forma diferente, apenas de forma contrária, ou seja: libertá-la da moral". ${ }^{27}$ Mas para Nietzsche os imoralistas ainda são "homens do dever" ${ }^{28}$ Seu dever, como filósofos, consiste em criar valores que promovam o florescimento do homem, que não se confunde com o "melhoramento" cristão. ${ }^{29}$ No seu caso, isso será realizado pela transvaloração dos valores, com os conceitos de eterno retorno, amor fati e Übermensch.

Ora, talvez fosse até menos problemático se Nietzsche tivesse permanecido num ceticismo moral. Mas ele foi além, propondo uma moral afirmativa, de caráter naturalista, cujos conceitos e relações entre si são complexos (como entender a relação o eterno retorno como tese naturalista e como imperativo ético, por exemplo?). ${ }^{30} \mathrm{~A}$ forma mais deflacionada de tentar compreender os conceitos da moral afirmativa de Nietzsche é vê-los como exortações para o estímulo do florescimento humano, fórmulas para promover formas diferentes de vida e cultivar virtudes altivas, sem o fanatismo dogmático que fundava a moral cristã. Esses conceitos teriam um caráter regulador, ficcional, tendo por fim fomentar a excelência humana, já que o homem, para Nietzsche, está sempre em processo, e por isso sempre passível de recriar a si mesmo e suas normas.

Esse tipo de interpretação permite atualizar a ética nietzschiana sem cair

27 Fragmento Póstumo 23 [3] de outubro de I888. KSA I3.603-604.

28 Para além de Bem e Mal\$226. KSA 5.I62.

29 Crepuisculo dos Ídolos, "Os 'melhoradores da humanidade”, KSA 6.98-IO2.

30 Marton, 2000. 
nas armadilhas de um naturalismo ontológico. Ela permite, também, um diálogo com as mais interessantes tentativas de formular uma ética naturalista. E, de fato, o projeto genealógico de Nietzsche favorece esse diálogo, que podemos realizar com a proposta de um "projeto ético" de Philip Kitcher.

Em seu artigo "Is a naturalized ethics possible?", Kitcher $^{3 \mathrm{I}}$, um crítico arguto de tentativas mais ambiciosas de naturalização da moral, como a sociobiologia, responde afirmativamente à questão posta por seu título. Para isso, inicialmente, numa parte descritiva, ele apresenta sua genealogia, que em muitos aspectos se assemelha à genealogia nietzschiana. Em ambas encontramos um processo de hominização de um animal beligerante, que teve de passar por um processo de socialização. Nesse processo, o que manteve a comunidade pacificada foi a aplicação de castigos àqueles que não seguiam as regras impostas pelo grupo. Para isso, foi necessário não só o desenvolvimento cognitivo da consciência, como também o reconhecimento das ações alheias como intencionais. Num estádio posterior, ocorre a criação de uma divindade como espécie de vigia das ações humanas e o surgimento dos guias religiosos como intermediários de Deus, que ganham assim proeminência sobre as normas da comunidade. Para Kitcher, a fundamentação da moral da religião é um equívoco, mas, por outro lado, a filosofia moral apenas criaria substitutos seculares para a religião, só que com menos força normativa. Sua saída é compreender o surgimento e desenvolvimento da moral como um "projeto ético", que pressupõe um progresso por meio da constituição de uma conversação ideal e da compreensão pragmatista de que é lidando com os problemas morais que soluçóes podem ser encontradas para dar continuidade a esse processo que é o projeto ético.

Vemos que, ao aproximar as duas genealogias, encontramos no projeto ético de Kitcher a questão que separa Nietzsche de outras formulaçôes éticas: a ideia de progresso moral como tácita aceitação da moral vigente. Para Nietzsche, Kitcher seria mais um "melhorador" da humanidade, e não um promotor da excelência humana. Mas Kitcher está atento a isso. Segundo ele, as possibilidades de florescimento do homem permitem dois pontos de vista, um igualitário e outro perfeccionista ${ }^{32}$ :

A sugestão óbvia é que a evolução do projeto transformou a vida humana, fornecendo possibilidades dramaticamente diferentes de florescimento humano, e, uma vez que elas estejam disponíveis, o problema central torna-se o de permitir aqueles que são capazes de realizá-las o façam. Poderíamos esquecer as aspirações medíocres dos muitos ("o rebanho") e promover a vida gloriosa dos poucos ("os espíritos livres").

31 Kitcher, 2014.

32 Kitcher, 20I4, p. 252. 
Nietzsche representa o mais profundo desafio à versão democrática (igualitária) da ética naturalista que eu elogiei”. ${ }^{33}$

\section{Referências}

Acampora, C. D. "Naturalism and Nietzsche's Moral Phychology". In: Ansell Pearson, K. A Companion to Nietzsche. Oxford: Blackwell, 2006, pp. 314-333.

Brobjer, T. Nietzsche's Ethics of Character. Uppsala: Uppsala University, I995.

Clark, M. \& Dudrick, D. "The Naturalisms of Beyond Good and Evil". In: Ansell Pearson, K. A Companion to Nietzsche. Oxford: Blackwell, 2006, pp. I48-I67.

De Caro, M. \& Macarthur, D. (Orgs.). Naturalism and normativity. New York: Columbia University Press, 2010.

Dennet, D. A Perigosa Ideia de Darwin. Rio de Janeiro: Rocco, 1998.

Hume, D. Tratado da natureza Humana. São Paulo: Editora da Unesp, 2000.

Janaway, C. Beyond Selflessness: Reading Nietzsche's Genealogy. New York, Oxford University Press, 2007.

Joyce, R. The Evolution of Morality. Cambridge, Massachusetts: MIT Press, 2007.

Kitcher, P. "Is a naturalized ethics possible?". In: Behaviour, v. I5I, 20I4, pp. $245-260$.

Knobe, J. \& Leiter, B. "The Case for Nietzschean Moral Psychology". In: Leiter, B. \& Sinhababu, N. Nietzsche and Morality. Oxford: Oxford University Press, 2007, pp. 83-I09.

Leiter, B. Nietzsche on Morality. New York: Routledge, 2002.

Leiter, B. "O naturalismo de Nietzsche reconsiderado". In: Cadernos Nietzsche, v. 29, 20II, pp. 77-I26.

Lopes, R. "A ambicionada assimilac ão do materialismo: Nietzsche e o debate naturalista na filosofia alemã da segunda metade do século xIx". In: Cadernos Nietzsche, v. 29, 2011, pp. 309-352.

Marton, S. "O eterno retorno do mesmo: Tese cosmológica ou imperativo ético”. In: Extravagâncias. São Paulo/Ijuí: Discurso/Unijuí: 2000, pp. 67-94.

Moore, G. \& Brobjer. Nietzsche and Science. New York: Routledge, 2004.

Nietzsche, F. Sämtliche Werke. Kritische Studienausgabe (кsa). I5 vols. Organizada por Giorgio Colli e Mazzino Montinari. Berlin: Walter de Gruyter, I988.

33 Kitcher, 20I4, p. 258. Kitcher defende que um cultivo universal, igualitário, englobaria o programa nietzschiano, algo com que Nietzsche certamente não concordaria. 
PrInZ, J. "Genealogies of Morals: Nietzsche's Method Compared". In: Journal of Nietzsche Studies, vol. 47, n. 2, Summer 2016, pp. 180-201.

RéE, P. Der Ursprung der moralischen Empfindungen. In: Gesammelte Werke (18751885). Supplementa Nietzscheana, vol. 7. Berlin: Walter de Gruyter, 2004.

SaAR, M. \& Wiesmann, H. G. Simon May (Ed.), Nietzsche's Genealogy of Morality: A Critical Guide, Cambridge University Press, 20II (Review). In: Notre Dame Philosophical Reviews, 07/03/20I2. https://ndpr.nd.edu/news/nietzsche-s-genealogy-of-morality-a-critical-guide-3/<acesso em ir/o3/20I8>.

Schaсht, R. "Nietzschean Normativity". In: Schacht. Nietzsche's Postmoralism. Cambridge: Cambridge University Press, 200I, pp. I49-180.

Sснаснт, R. "O Naturalismo de Nietzsche". In: Cadernos Nietzsche, v. 29, 20II, pp. 35-75.

Schacht, R. "Nietzsche's Naturalism and Normativity". In: Janaway, C. \& RoBertson, S. (Orgs.). Nietzsche, Naturalism and Normativity. Oxford: Oxford University Press, 20I2, pp. 236-258. 